\title{
Agrococcus versicolor sp. nov., an actinobacterium associated with the phyllosphere of potato plants
}

Correspondence Undine Behrendt ubehrendt@zalf.de

\section{Undine Behrendt, ${ }^{1}$ Peter Schumann ${ }^{2}$ and Andreas Ulrich ${ }^{1}$}

\author{
${ }^{1}$ Leibniz-Centre for Agricultural Landscape Research (ZALF), Institute of Landscape Matter \\ Dynamics, Eberswalder Straße 84, D-15374 Müncheberg, Germany \\ ${ }^{2}$ DSMZ - German Collection of Microorganisms and Cell Cultures, Inhoffenstraße 7B, D-38124 \\ Braunschweig, Germany
}

\begin{abstract}
The taxonomic position of a group of actinobacterial strains isolated from the phyllosphere of potato plants was investigated by using a polyphasic approach. Although the similarity values for their 16S rRNA gene sequences suggested an intermediate position between Microbacterium and Agrococcus, the phylogenetic tree demonstrated a clear clustering of the representative strain, $\mathrm{K} 114 / 01^{\top}$, within the genus Agrococcus. The presence of 2,4-diaminobutyric acid as the diagnostic diamino acid in the cell-wall peptidoglycan of strain $\mathrm{K} 114 / 01^{\top}$ substantiated the affiliation to the genus Agrococcus. An analysis performed using matrix-assisted laser desorption ionization-time-of-flight mass spectrometry revealed highly similar spectral patterns for the isolated strains, which, together with their conformity regarding a multitude of phenotypic features, supported their affiliation to the same species. Differences in several physiological features, peptidoglycan and menaquinone composition and whole-cell fatty acid profiles enabled discrimination of the phyllosphere isolates with respect to recognized Agrococcus species. As the 16S rRNA gene sequence similarity values were below $97 \%$, the strains isolated from the phyllosphere of potato plants represent a novel species of the genus Agrococcus, for which the name Agrococcus versicolor sp. nov. is proposed. The type strain is $\mathrm{K} 114 / 01^{\top}$ (=DSM $19812^{\top}$ $=$ LMG $24386^{\top}$ ).
\end{abstract}

The plant phyllosphere is known to be a typical habitat for several genera of the family Microbacteriaceae. The species of the genera Microbacterium, Leifsonia, Curtobacterium, Clavibacter, Frigoribacterium, Agreia and Plantibacter, in particular, colonize the surfaces of various plant species (Evtushenko \& Takeuchi, 2006). In contrast, Agrococcus species have not been isolated from plant surfaces. Strains of this genus have been found in the air, in soil samples of different origins, on a medieval wall painting and on the surfaces of some cheeses (Groth et al., 1996; Wieser et al., 1999; Zlamala et al., 2002; Mayilraj et al., 2006; Bora et al., 2007). Furthermore, the members of the genus are able to thrive under extreme living conditions, such as in permafrost environments (Katayama et al., 2007; Zhang et al., 2007), in extreme alkaline groundwater (Tiago et al., 2004) or in limiting environments (clean rooms; La Duc et al., 2007).

In the context of studying the effects of transgenic fructanproducing potatoes on the diversity of the microbial

Abbreviations: DAB, 2,4-diaminobutyric acid; MALDI-TOF, matrixassisted laser desorption ionization-time-of-flight.

The GenBank/EMBL/DDBJ accession number for the 16S rRNA gene sequence of strain $\mathrm{K} 114 / 01^{\top}$ is $\mathrm{AM} 940157$. communities in the phyllosphere, actinobacterial species were found to constitute a significant proportion of the colonizing bacteria. A relatively large number of bacterial taxa belonging to the family Microbacteriaceae were found on an isogenic potato line in comparison with the transgenic lines. Within this group, several strains were isolated that displayed characteristics of the genus Agrococcus. A comparative analysis of the 16S rRNA gene sequences indicated that these strains represent a novel species within this genus. The aim of this study was to describe the novel species on the basis of data collected by using a polyphasic approach.

To study the diversity of the bacterial community, samples from the phyllosphere of the investigated potato lines were processed as described by Heuer \& Smalla (1999). Estimation of population densities and screening for bacterial isolates were performed using different culture media. Heterotrophic bacteria were determined on tryptic soy agar (Merck) and nutrient agar (SIFIN) supplemented with cycloheximide $\left(0.4 \mathrm{~g} \mathrm{l}^{-1}\right)$ and incubated at $21{ }^{\circ} \mathrm{C}$ for 7 days. To determine the abundance of bacterial taxa, some representative colonies were isolated from each medium, purified and then stored at $-80{ }^{\circ} \mathrm{C}$ in nutrient broth (SIFIN) containing $40 \%$ glycerol until further processing. 
The isolates were grouped on the basis of morphological and physiological tests, as described previously (Behrendt et al., 1997, 1999). Representative strains selected from groups with uncertain affiliation at the genus level were investigated using partial sequence analysis of the $16 \mathrm{~S}$ rRNA gene, as described by Ulrich et al. (2008). Strains $\mathrm{K} 114 / 01^{\mathrm{T}}$ and $\mathrm{K} 35 / 01$ (isolated from nutrient agar) and strain K 42/01 (isolated from tryptic soy agar) were tentatively assigned to the genus Agrococcus and subjected to further taxonomic investigation.

Phylogenetic analysis of a representative strain, $\mathrm{K} 114 / 01^{\mathrm{T}}$, on the basis of the 16S rRNA gene sequence was performed as described by Behrendt et al. (2003). Phylogenetic trees were based on a $1420 \mathrm{nt}$ alignment (Escherichia coli positions 50-1458) and constructed using the neighbourjoining (Saitou \& Nei, 1987) and maximum-likelihood (Felsenstein, 1981) algorithms (PHYLIP, version 3.6; Felsenstein, 1993). The closest phylogenetic neighbours of strain $\mathrm{K} 114 / 01^{\mathrm{T}}$, as determined from a pairwise sequence comparison, were the type strains of Microbacterium deminutum and Agrococcus jenensis, with similarities of 97.1 and $96.9 \%$, respectively. Although the 16S rRNA gene sequence similarity for strain $\mathrm{K} 114 / 01^{\mathrm{T}}$ was slightly greater with respect to the species $M$. deminutum, it clustered with the established species of the genus Agrococcus (Fig. 1). This phylogenetic position was confirmed by the maximumlikelihood tree and was supported by a bootstrap value that was greater than $50 \%$. Correspondingly, M. deminutum $\mathrm{KV}-483^{\mathrm{T}}$ formed a cluster with species of the genus Microbacterium with both treeing methods (Fig. 1). This position was supported by high bootstrap percentages (86 and 92\%). As reviewed by Stackebrandt et al. (2007), the topology of phylogenetic trees in the family Microbacteriaceae changes depending on the strain set selected for analysis. For this reason, another tree comprising all type strains of the family was constructed in addition to the tree shown in Fig. 1, which is based on the established species of Agrococcus and representative species for the other genera. In the extended tree, the results were similar to those obtained in the tree shown in Fig. 1. Strain $\mathrm{K} 114 / 01^{\mathrm{T}}$ clearly clustered with the species of the genus Agrococcus, and all species of the genus Microbacterium formed a monophyletic branch that clustered next to the genera Okibacterium and Plantibacter (data not shown). These results indicated the affiliation of strain $\mathrm{K} 114 / 01^{\mathrm{T}}$ to the genus Agrococcus. Furthermore, similarity values below $97 \%$ were obtained with respect to the $16 \mathrm{~S}$ rRNA gene sequences of established species of the genus Agrococcus, suggesting a separate species position for the isolate.

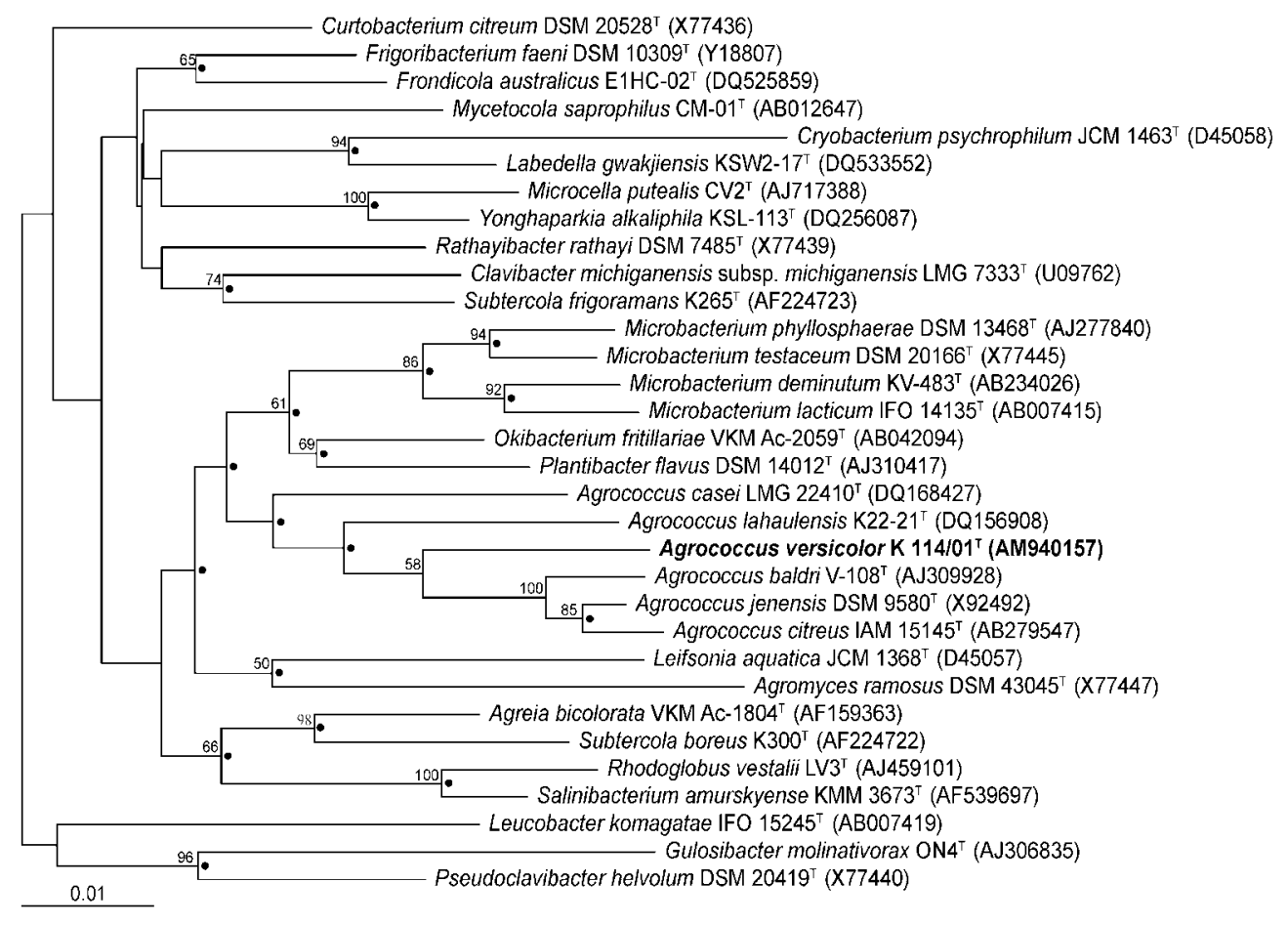

Fig. 1. Neighbour-joining tree, based on almost-complete $16 \mathrm{~S}$ rRNA gene sequences, showing the relationships between strain $\mathrm{K} 114 / 01^{\top}$ and established species of Agrococcus and representative strains from all genera of the family Microbacteriaceae. Filled circles indicate branches of the tree that were also obtained using the maximum-likelihood method (Felsenstein, 1981). The sequence of Arthrobacter globiformis DSM 20124 ${ }^{\top}$ (GenBank accession no. M23411) was used as an outgroup (not shown). Numbers at nodes indicate bootstrap percentages $>50 \%$ (based on 1000 resampled datasets). Bar, 0.01 changes per nucleotide position. 
A significant chemotaxonomic characteristic for genus affiliation in the family Microbacteriaceae is the amino acid composition of the cell wall. The amino acids and peptides in cell-wall hydrolysates of the peptidoglycan of strain $\mathrm{K}$ $114 / 01^{\mathrm{T}}$ were analysed using two-dimensional ascending TLC on cellulose plates with the solvent system described by Schleifer \& Kandler (1972). The characteristic cell-wall diamino acid was 2,4-diaminobutyric acid (DAB), which is typical for the genus Agrococcus (Evtushenko \& Takeuchi, 2006). In contrast, species of the genus Microbacterium are characterized by the presence of ornithine or lysine as the diagnostic diamino acid (Evtushenko \& Takeuchi, 2006). Thus, the cell-wall composition substantiates the affiliation of strain K $114 / 01^{\mathrm{T}}$ to the genus Agrococcus. In addition to $\mathrm{DAB}$, the amino acids alanine, glycine, threonine, aspartic acid and glutamic acid were detected. The cell-wall Ala/ Gly/Thr/DAB/Asp/Glu ratio was $2.3: 2.1: 2.5: 0.8: 0.9: 1.0$. This composition is very similar to that of $A$. jenensis (Groth et al., 1996), its closest phylogenetic neighbour in the genus. The same qualitative amino acid composition was reported for the peptidoglycan of Agrococcus lahaulensis (Mayilraj et al., 2006), while Agrococcus baldri (Zlamala et al., 2002) and Agrococcus citreus (Wieser et al., 1999) lacked threonine and Agrococcus casei (Bora et al., 2007) lacked both threonine and aspartic acid.

Since the phylogenetic analysis and the investigation of the cell-wall composition were only performed for strain $\mathrm{K} 114 / 01^{\mathrm{T}}$, it was necessary to determine the similarity at the species level for isolates K 35/01 and K 42/01. Recent studies demonstrated the ability of matrix-assisted laser desorption ionization-time-of-flight mass spectrometry (MALDI-TOF MS) to permit the identification of bacteria at the species level in pure culture under carefully controlled culture and analysis conditions (Conway et al., 2001; Fenselau \& Demirev, 2001; Valentine et al., 2005). Furthermore, spectra from MALDI-TOF MS reflect the phylogenetic relationship of micro-organisms, corresponding with the results of sequence analyses of conservative genes (Stackebrandt et al., 2005). MALDI-TOF MS analysis was performed according to the method described by Tóth et al. (2008). As shown in Fig. 2, the isolates formed a tight cluster that was separable on the basis of clear spectral dissimilarities with respect to all type strains of the genus Agrococcus. The high level of spectral similarity between the phyllosphere isolates indicated their affiliation to the same species.

The phyllosphere isolates were also subjected to a multitude of phenotypic tests to determine their similarities. Standard tests for morphological and physiological characterization were performed as described by Behrendt et al. (1999). All strains were cultivated on nutrient agar or in the respective broth at $21{ }^{\circ} \mathrm{C}$. Production of $\mathrm{L}$ phenylalanine deaminase was investigated according to the method described by Richard \& Kiredjian (1995). Hydrogen sulphide production was tested on Kligler iron agar (Oxoid) and the hydrolysis of L-tyrosine was determined on nutrient agar supplemented with $0.5 \%$

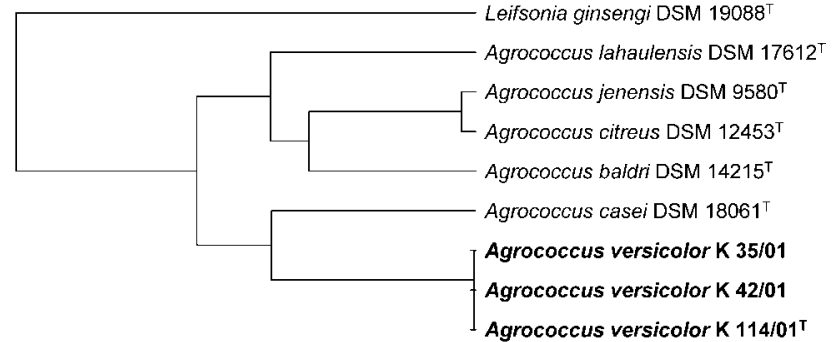

$1000 \quad 900 \quad 800 \quad 700 \quad 600 \quad 500 \quad 400 \quad 300 \quad 200 \quad 100$

Distance

Fig. 2. Dendrogram, generated by the BioTyper program (version 1.1; Bruker Daltonics), showing the similarities of MALDI-TOF mass spectra of cell extracts from strains $\mathrm{K} 114 / 01^{\top}, \mathrm{K} \mathrm{35/01}$, K 42/01 and type strains of the genus Agrococcus. The mass spectrum of Leifsonia ginsengi DSM $19088^{\top}$ served as an outgroup.

(w/v) L-tyrosine. Oxidation of carbon sources was tested using Biolog GP2 microplates. The instructions of the manufacturer were modified in that the strains were cultivated on tryptic soy agar (Mayilraj et al., 2006). Results were read visually after 24 and $48 \mathrm{~h}$ incubation at $30{ }^{\circ} \mathrm{C}$. Oxidative acid production from carbohydrates was investigated using API $50 \mathrm{CH}$ strips (bioMérieux) inoculated with a bacterial suspension in $\mathrm{CHB} / \mathrm{E}$ medium (bioMérieux). The results were not read until after $72 \mathrm{~h}$, as the strains tested showed delayed reactions. API 20NE (bioMérieux) test strips were applied to determine additional physiological and biochemical features. The phyllosphere isolates displayed high levels of conformity with regard to phenotypic features. On the GP2 microplates, in particular, identical reactions were obtained for all 95 carbohydrates. Furthermore, the API $50 \mathrm{CH}$ results for acid production were very similar. Different reactions were found only for oxidative acid production from Dmannitol, $\mathrm{N}$-acetylglucosamine, cellobiose and maltose. Whilst strain $\mathrm{K} 114 / 01^{\mathrm{T}}$ did not show a reaction for these carbohydrates, acid production for strains $\mathrm{K} 35 / 01$ and K 42/01 was weak for D-mannitol and $\mathrm{N}$-acetylglucosamine but positive for cellobiose and maltose. These results supported those of the MALDI-TOF MS analysis, i.e. that all three isolates represented one species. Details of the morphological and physiological features of the strains are given in the species description. Characteristics that serve to differentiate the phyllosphere isolates from established species of the genus Agrococcus are presented in Table 1. The isolates were clearly distinguishable from these Agrococcus species on the basis of their ability to use several carbohydrates on the GP2 microplates.

A further prominent taxonomic feature that characterized the isolates and served to differentiate them from related species was their whole-cell fatty acid profiles. Fatty acid methyl esters were extracted from cells cultivated on tryptic soy agar for 1 day at $28{ }^{\circ} \mathrm{C}$ and were then analysed with the 
Table 1. Differential phenotypic characteristics of Agrococcus species

Taxa: 1, A. versicolor sp. nov.; 2, A. baldri; 3, A. casei; 4, A. citreus; 5, A. lahaulensis; 6, A. jenensis. Data are from Groth et al. (1996), Wieser et al. (1999), Zlamala et al. (2002), Mayilraj et al. (2006), Bora et al. (2007) and this study. +, Positive; -, negative; w, weak reaction; -/+, different reactions obtained by the authors; $\mathrm{D}$, delayed reaction, ND, no data available.

\begin{tabular}{|c|c|c|c|c|c|c|}
\hline Characteristic & 1 & 2 & $3^{*}$ & 4 & 5 & 6 \\
\hline Amino acids of the peptidoglycan & $\begin{array}{l}\text { Ala, Gly, Thr, } \\
\text { DAB, Asp, Glu }\end{array}$ & $\begin{array}{c}\text { Ala, Gly, DAB, } \\
\text { Asp, Glu }\end{array}$ & $\begin{array}{c}\text { Ala, Gly, DAB, } \\
\text { Glu }\end{array}$ & $\begin{array}{c}\text { Ala, Gly, DAB, } \\
\text { Asp, Glu }\end{array}$ & $\begin{array}{l}\text { Ala, Gly, Thr, } \\
\text { DAB, Asp, Glu } \dagger\end{array}$ & $\begin{array}{l}\text { Ala, Gly, Thr, } \\
\text { DAB, Asp, Glu }\end{array}$ \\
\hline Growth with $6.5 \% \mathrm{NaCl}$ & - & $-1+$ & ND & + & + & + \\
\hline \multicolumn{7}{|l|}{ Hydrolysis of: } \\
\hline Aesculin & + & $-1+$ & - & + & - & + \\
\hline Tyrosine & - & - & - & + & - & + \\
\hline Casein & + & - & - & - & + & $-1+$ \\
\hline Gelatin & $\mathrm{D}$ & - & ND & - & + & - \\
\hline Starch & - & + & + & + & + & + \\
\hline \multicolumn{7}{|l|}{ Utilization on Biolog GP2 microplates } \\
\hline Dextrin & + & - & - & - & + & - \\
\hline Tweens 40 and 80 & - & - & + & - & - & - \\
\hline$N$-Acetyl-D-glucosamine & + & - & - & - & - & - \\
\hline L-Arabinose & + & + & - & + & + & + \\
\hline D-Fructose & + & + & - & + & + & + \\
\hline D-Gluconic acid & + & + & - & + & - & + \\
\hline$\alpha$-D-Glucose & + & + & - & - & - & + \\
\hline Maltotriose & + & - & - & - & + & - \\
\hline D-Mannose & + & + & - & + & - & + \\
\hline D-Psicose & + & + & + & + & - & + \\
\hline L-Rhamnose & - & - & - & - & + & - \\
\hline D-Sorbitol & - & + & $\mathrm{w}$ & - & - & - \\
\hline Sucrose & + & - & - & - & - & - \\
\hline D-Tagatose & $\mathrm{w}$ & + & - & - & - & - \\
\hline Trehalose & + & - & $\mathrm{w}$ & - & - & - \\
\hline Turanose & + & - & - & + & - & - \\
\hline D-Xylose & + & + & - & + & + & + \\
\hline$\alpha$-Ketovaleric acid & $\mathrm{w}$ & - & $\mathrm{w}$ & - & - & - \\
\hline Methyl pyruvate & - & - & + & - & - & - \\
\hline Propionic acid & $\mathrm{W}$ & - & $\mathrm{w}$ & - & - & - \\
\hline $\mathrm{N}$-Acetyl L-glutamic acid & - & - & + & - & - & - \\
\hline L-Alaninamide & + & - & - & - & - & + \\
\hline Glycerol & + & + & + & - & + & - \\
\hline Adenosine & + & + & + & - & + & - \\
\hline $2^{\prime}$-Deoxyadenosine & - & - & + & - & + & + \\
\hline Inosine & - & - & - & - & + & - \\
\hline Thymidine & - & + & + & - & + & - \\
\hline D-Fructose 6-phosphate & - & - & - & + & - & - \\
\hline
\end{tabular}

${ }^{\star}$ Hydrolysis of tyrosine and casein as well as reactions on Biolog GP2 were determined in this study for A. casei DSM $18061^{\mathrm{T}}$. $\dagger$ Determined in this study for A. lahaulensis $\mathrm{K} 22-21^{\mathrm{T}}$.

Sherlock Microbial Identification system (MIDI, version 4.5) as described by Behrendt et al. (1999). As shown in Table 2, the cellular fatty acid profiles of the potato isolates were relatively similar, supporting the suggestion that they represent one species. The major fatty acids were anteiso$\mathrm{C}_{15: 0} \quad(39.8 \pm 3.3 \%), \quad$ iso- $\mathrm{C}_{15: 0} \quad(17.1 \pm 1.6 \%), \quad \mathrm{C}_{16: 0}$ $(13.9 \pm 1.1 \%)$ and anteiso- $\mathrm{C}_{17: 1}(7.6 \pm 4.3 \%)$ and minor fatty acids were anteiso- $\mathrm{C}_{17: 0}(5.7 \pm 0.6 \%)$, iso- $\mathrm{C}_{16: 0}$
$(5.6 \pm 1.2 \%), \mathrm{C}_{14: 0}(3.0 \pm 0.2 \%)$, iso- $\mathrm{C}_{17: 0}(1.9 \pm 0.4 \%)$ and iso- $\mathrm{C}_{14: 0}(1.6 \pm 0.8 \%)$. Fatty acids typical of the genus, i.e. anteiso- $C_{15: 0}$, iso- $C_{15: 0}$, anteiso- $C_{17: 1}$ and iso- $C_{16: 0}$, were present in the isolates. Nevertheless, significant quantitative and qualitative differences were found in comparison with Agrococcus species. Notable differences were demonstrated in the quantities of the fatty acids $\mathrm{C}_{16: 0}$, iso- $\mathrm{C}_{15: 0}$ and anteiso- $\mathrm{C}_{17: 0}$ (Zlamala et al., 2002; 
Table 2. Cellular fatty acid compositions (\%) of the phyllosphere strains

ND, Not detected; tr, traces $(<1 \%)$.

\begin{tabular}{|c|c|c|c|}
\hline Fatty acid & $\mathrm{K} 114 / 01^{\mathrm{T}}$ & K 35/01 & K 42/01 \\
\hline iso- $\mathrm{C}_{13: 0}$ & 1.13 & $\operatorname{tr}$ & $\operatorname{tr}$ \\
\hline anteiso- $\mathrm{C}_{13: 0}$ & $\operatorname{tr}$ & $\operatorname{tr}$ & $\operatorname{tr}$ \\
\hline $\mathrm{C}_{14: 0}$ & 3.21 & 2.81 & 3.14 \\
\hline iso- $\mathrm{C}_{14: 0}$ & 2.55 & 1.00 & 1.17 \\
\hline $\mathrm{C}_{15: 0}$ & $\operatorname{tr}$ & $\operatorname{tr}$ & $\operatorname{tr}$ \\
\hline iso- $\mathrm{C}_{15: 0}$ & 15.29 & 18.37 & 17.70 \\
\hline anteiso- $\mathrm{C}_{15: 0}$ & 43.56 & 37.57 & 38.24 \\
\hline iso- $\mathrm{C}_{15: 1}$ & $\operatorname{tr}$ & 1.03 & 1.02 \\
\hline anteiso- $\mathrm{C}_{15: 1}$ & $\operatorname{tr}$ & $\operatorname{tr}$ & $\operatorname{tr}$ \\
\hline $\mathrm{C}_{16: 0}$ & 15.22 & 13.33 & 13.26 \\
\hline iso- $\mathrm{C}_{16: 0}$ & 7.06 & 4.89 & 4.99 \\
\hline iso- $\mathrm{C}_{17: 0}$ & 1.54 & 2.34 & 1.94 \\
\hline anteiso- $\mathrm{C}_{17: 0}$ & 5.07 & 6.29 & 5.69 \\
\hline anteiso- $\mathrm{C}_{17: 1}$ & 2.69 & 9.19 & 10.78 \\
\hline iso- $\mathrm{C}_{20: 0}$ & ND & 1.25 & $\mathrm{ND}$ \\
\hline
\end{tabular}

Mayilraj et al., 2006; Bora et al., 2007). The fatty acid anteiso- $\mathrm{C}_{17: 1}$ was found only in the potato isolates, whereas $\mathrm{C}_{14: 0}$ occurred also in the species $A$. jenensis, but only in trace amounts (Groth et al., 1996). Thus, a clear demarcation between the potato isolates and established Agrococcus species was possible on the basis of fatty acid profiles. The isoprenoid quinone composition was determined as described by Groth et al. (1996). The quinone system of strain $\mathrm{K} 114 / 01^{\mathrm{T}}$ consisted of the menaquinones MK-10, MK-11, MK-8 and MK-9 (ratio of peak areas $16: 16: 4: 2)$. MK-12, which is typical of all established species of the genus Agrococcus, could not be detected. MK10 was found as an additional major component (as in $A$. lahaulensis; Mayilraj et al., 2006).

In summary, the results of the phenotypic and phylogenetic analyses demonstrated that the isolates of the potato phyllosphere represent a novel species of the genus Agrococcus, for which the name Agrococcus versicolor sp. nov. is proposed.

\section{Description of Agrococcus versicolor sp. nov.}

Agrococcus versicolor (ver.si'co.lor. L. adj. versicolor colour changing).

Cells are asporogenous, non-motile, short to ovoid rods $(0.5-0.6 \times 0.8-1.2 \mu \mathrm{m})$ and occur singly or in pairs, sometimes forming small irregular clusters. Gram-positive and strictly aerobic. Colonies on nutrient agar are dark pink to red in colour and are smooth with regular margins. Young, solitary, growing colonies are yellow, turning dark pink with age. The optimal growth temperature is $21{ }^{\circ} \mathrm{C}$; no growth at 4 or $37^{\circ} \mathrm{C}$. Nitrate and nitrite are not reduced. Growth occurs at 1 and $2 \% \mathrm{NaCl}$ but not at higher concentrations. Catalase activity is present, but oxidase, urease, L-phenylalanine deaminase, lysine and ornithine decarboxylase, arginine dihydrolase and tryptophan deaminase activities are absent. $\beta$-Galactosidase activity is weak. Gelatin, casein and aesculin are hydrolysed, but starch and tyrosine are not. Hydrogen sulphide is not produced. Indole production from L-tryptophan and the reaction in the Voges-Proskauer test are negative. The following are utilized on Biolog microplates GP2: dextrin, $\mathrm{N}$-acetyl-D-glucosamine, L-arabinose, cellobiose, D-fructose, D-gluconic acid, $\alpha$-D-glucose, maltose, Dmannitol, D-mannose, palatinose, D-psicose, D-ribose, sucrose, D-tagatose, turanose, D-xylose, propionic acid and glycerol. Maltotriose, trehalose, $\alpha$-hydroxybutyric acid, $\alpha$-ketovaleric acid, L-alaninamide and adenosine are utilized with prolonged incubation. The following are not utilized: $\alpha$ - and $\beta$-cyclodextrin, glycogen, inulin, mannan, Tweens 40 and 80, $N$-acetyl-D-mannosamine, amygdalin, D-arabitol, arbutin, D-galactose, L-fucose, D-galacturonic acid, gentiobiose, myo-inositol, $\alpha$-D-lactose, lactulose, melezitose, melibiose, methyl $\alpha$-D-galactoside, methyl $\beta$ D-galactoside, methyl $\alpha$-D-glucoside, methyl $\beta$-D-glucoside, methyl $\alpha$-D-mannoside, raffinose, L-rhamnose, salicin, sedoheptulosan, D-sorbitol, stachyose, xylitol, acetic acid, $\beta$-hydroxybutyric acid, $\gamma$-hydroxybutyric acid, $p$-hydroxyphenylacetic acid, $\alpha$-ketoglutaric acid, lactamide, D-lactic acid methyl ester, L-lactic acid, D- and Lmalic acid, monomethyl succinate, succinamic acid, succinic acid, $\mathrm{N}$-acetyl L-glutamic acid, D- and L-alanine, L-alanyl glycine, L-asparagine, L-glutamic acid, glycyl Lglutamic acid, L-pyroglutamic acid, L-serine, putrescine, 2,3-butanediol, 2'-deoxyadenosine, inosine, thymidine, uridine, adenosine $5^{\prime}$-monophosphate, thymidine $5^{\prime}$ monophosphate, uridine $5^{\prime}$-monophosphate, $\alpha$-D-glucose 1-phosphate, D-glucose 6-phosphate and DL- $\alpha$-glycerol phosphate. Oxidative acid production with API $50 \mathrm{CH}$ is positive for ribose and L-arabinose but weak for D-glucose, D-fructose, D-mannose, sucrose and turanose. Acid production is negative for glycerol, erythritol, D-arabinose, L-xylose, D-adonitol, methyl $\beta$-D-xylopyranoside, D-galactose, L-sorbose, L-rhamnose, dulcitol, inositol, D-sorbitol, methyl $\alpha$-D-mannopyranoside, methyl $\alpha$-D-glucopyranoside, amygdalin, arbutin, salicin, D-lactose (bovine origin), melibiose, trehalose, inulin, melezitose, raffinose, starch, glycogen, xylitol, gentiobiose, D-lyxose, D-tagatose, D- and L-fucose, D- and L-arabitol, potassium gluconate, potassium 2-ketogluconate and potassium 5-ketogluconate. Strain-specific reactions are shown for D-mannitol, $\mathrm{N}$ acetylglucosamine, D-cellobiose and maltose. The diagnostic cell-wall diamino acid is DAB; alanine, glycine, threonine, aspartic acid and glutamic acid are also present. The major fatty acids are anteiso- $\mathrm{C}_{15: 0}$, iso- $\mathrm{C}_{15: 0}, \mathrm{C}_{16: 0}$ and anteiso- $\mathrm{C}_{17: 1}$ and minor fatty acids are anteiso- $\mathrm{C}_{17: 0}$, iso- $\mathrm{C}_{16: 0}, \mathrm{C}_{14: 0}$, iso- $\mathrm{C}_{17: 0}$ and iso- $\mathrm{C}_{14: 0}$. The major menaquinones are MK-10 and MK-11.

The type strain, $\mathrm{K} 114 / 01^{\mathrm{T}}$ (=DSM $19812^{\mathrm{T}}=\mathrm{LMG}$ $24386^{\mathrm{T}}$ ), was isolated from the phyllosphere of potato plants in Dahnsdorf, Germany. 


\section{Acknowledgements}

This work was supported by the Federal Ministry of Education and Research (grant 0312632D). We wish to thank Mrs B. Selch, Mrs S. Weinert (ZALF, Müncheberg), Mrs G. Pötter and Mrs A. Wasner (DSMZ, Braunschweig) for their excellent technical assistance. Furthermore, we would like to acknowledge Professor Dr H. G. Trüper (Rheinische Friedrich-Wilhelm-Universität, Bonn) for his help with the Latin construction of the species name.

\section{References}

Behrendt, U., Müller, T. \& Seyfarth, W. (1997). The influence of extensification in grassland management on the populations of micro-organisms in the phyllosphere of grasses. Microbiol Res 152, 75-85.

Behrendt, U., Ulrich, A., Schumann, P., Erler, W., Burghardt, J. \& Seyfarth, W. (1999). A taxonomic study of bacteria isolated from grasses: a proposed new species Pseudomonas graminis sp. nov. Int $J$ Syst Bacteriol 49, 297-308.

Behrendt, U., Ulrich, A. \& Schumann, P. (2003). Fluorescent pseudomonads associated with the phyllosphere of grasses; Pseudomonas trivialis sp. nov., Pseudomonas poae sp. nov. and Pseudomonas congelans sp. nov. Int J Syst Evol Microbiol 53, 1461-1469.

Bora, N., Vancanneyt, M., Gelsomino, R., Swings, J., Brennan, N., Cogan, T. M., Larpin, S., Desmasures, N., Lechner, F. E. \& other authors (2007). Agrococcus casei sp. nov., isolated from the surfaces of smear-ripened cheeses. Int J Syst Evol Microbiol 57, 92-97.

Conway, G. C., Smole, S. C., Sarracino, D. A., Arbeit, R. D. \& Leopold, P. E. (2001). Phyloproteomics: species identification of Enterobacteriaceae using matrix-assisted laser desorption/ionization time-of-flight mass spectrometry. J Mol Microbiol Biotechnol 3, 103112.

Evtushenko, L. I. \& Takeuchi, M. (2006). The family Microbacteriaceae. In The Prokaryotes; a Handbook on the Biology of Bacteria, 3rd edn, vol. 3, pp. 1020-1098. Edited by M. Dworkin, S. Falkow, E. Rosenberg, K. H. Schleifer \& E. Stackebrandt. New York: Springer.

Felsenstein, J. (1981). Evolutionary tree from DNA sequences: a maximum likelihood approach. J Mol Evol 17, 368-376.

Felsenstein, J. (1993). PHYLIP (phylogeny inference package), version 3.5c. Distributed by the author. Department of Genome Sciences, University of Washington, Seattle, USA.

Fenselau, C. \& Demirev, P. A. (2001). Characterization of intact microorganisms by Maldi mass spectrometry. Mass Spectrom Rev 20, 157-171.

Groth, I., Schumann, P., Weiss, N., Martin, K. \& Rainey, F. A. (1996). Agrococcus jenensis gen. nov., sp. nov., a new genus of actinomycetes with diaminobutyric acid in the cell wall. Int J Syst Bacteriol 46, 234-239.

Heuer, H. \& Smalla, K. (1999). Bacterial phyllosphere communities of Solanum tuberosum L. and T4-lysozyme-producing transgenic variants. FEMS Microbiol Ecol 28, 357-371.
Katayama, T., Tanaka, M., Moriizumi, J., Nakamura, T., Brouchkov, A., Douglas, T. A., Fukuda, M., Tomita, F. \& Asano, K. (2007). Phylogenetic analysis of bacteria preserved in a permafrost ice wedge for 25,000 years. Appl Environ Microbiol 73, 2360-2363.

La Duc, M. T., Dekas, A., Osman, S., Moissl, C., Newcombe, D. \& Venkateswaran, K. (2007). Isolation and characterization of bacteria capable of tolerating the extreme conditions of clean room environments. Appl Environ Microbiol 73, 2600-2611.

Mayilraj, S., Suresh, K., Schumann, P., Kroppenstedt, R. M. \& Saini, H. S. (2006). Agrococcus lahaulensis sp. nov., isolated from a cold desert of the Indian Himalayas. Int J Syst Evol Microbiol 56, 1807-1810.

Richard, C. \& Kiredjian, M. (1995). Laboratory Methods for the Identification of Strictly Aerobic Gram-Negative Bacilli. Paris: Institut Pasteur.

Saitou, N. \& Nei, M. (1987). The neighbor-joining method: a new method for reconstructing phylogenetic trees. Mol Biol Evol 4, 406-425.

Schleifer, K. H. \& Kandler, O. (1972). Peptidoglycan types of bacterial cell walls and their taxonomic implications. Bacteriol Rev 36, 407-477.

Stackebrandt, E., Päuker, O. \& Erhard, M. (2005). Grouping myxococci (Corallococcus) strains by matrix-assisted laser desorption ionization time-of-flight (MALDI TOF) mass spectrometry: comparison with gene sequence phylogenies. Curr Microbiol 50, 71-77.

Stackebrandt, E., Brambilla, E. \& Richert, K. (2007). Gene sequence phylogenies of the family Microbacteriaceae. Curr Microbiol 55, 42-46.

Tiago, I., Chung, A. P. \& Verissimo, A. (2004). Bacterial diversity in a nonsaline alkaline environment: heterotrophic aerobic populations. Appl Environ Microbiol 70, 7378-7387.

Tóth, E. M., Schumann, P., Borsodi, A. K., Kéki, Z., Kovács, A. L. \& Márialigeti, K. (2008). Wohlfahrtiimonas chitiniclastica gen. nov., sp. nov., a new gammaproteobacterium isolated from Wohlfahrtia magnifica (Diptera: Sarcophagidae). Int J Syst Evol Microbiol 58, 976-981.

Ulrich, K., Ulrich, A. \& Ewald, D. (2008). Diversity of endophytic bacterial communities in poplar grown under field conditions. FEMS Microbiol Ecol 63, 169-180.

Valentine, N., Wunschel, S., Wunschel, D., Petersen, C. \& Wahl, K. (2005). Effect of culture conditions on microorganism identification by matrix-assisted laser desorption ionization mass spectrometry. Appl Environ Microbiol 71, 58-64.

Wieser, M., Schumann, P., Martin, K., Altenburger, P., Burghardt, J., Lubitz, W. \& Busse, H. J. (1999). Agrococcus citreus sp. nov., isolated from a medieval wall painting of the chapel of Castle Herberstein (Austria). Int J Syst Bacteriol 49, 1165-1170.

Zhang, G., Niu, F., Ma, X., Liu, W., Dong, M., Feng, H., An, L. \& Cheng, G. (2007). Phylogenetic diversity of bacteria isolates from the Qinghai-Tibet Plateau permafrost region. Can J Microbiol 53, 10001010 .

Zlamala, C., Schumann, P., Kämpfer, P., Rosselló-Mora, R., Lubitz, W. \& Busse, H.-J. (2002). Agrococcus baldri sp. nov., isolated from the air in the 'Virgilkapelle' in Vienna. Int J Syst Evol Microbiol 52, 1211-1216. 